\title{
A Novel Therapy of Eosinophilic Esophagitis-Treatment of Eosinophilic Esophagitis Using a Single Dose of Intramuscular Corticosteroid and Proton Pump Inhibitor
}

\author{
Augusto Fey ${ }^{1,2}$, Lorete Maria da Silva Kotze ${ }^{2}$ and Mônica Serapião ${ }^{1}$ \\ 1. Faculty of Medicine, UNIDAVI, Rio do Sul 89160-932, Brazil \\ 2. Department of Health Sciences, Pontifical Catholic University, Curitiba 80215-901, Brazil
}

\begin{abstract}
Background: Ee (Eosinophilic esophagitis) is an inflammatory condition characterized by a dense eosinophilic infiltrate in the esophageal epithelium. Its pathophysiology mimics that of allergic esophagitis, and evolves clinically as a chronic disease with periods of exacerbation. Symptoms and endoscopic findings are usually non-specific and similar to those of other esophageal illnesses. The mainstay of treatment of Ee is with corticosteroids and/or specific diets, which have been shown to cause symptom remission and histological improvement. Aim: The objective of this study was to demonstrate the efficacy of a novel and promising treatment protocol for Ee. Materials and methods: We prospectively evaluated 24 patients with Ee over two years. Patients were treated with a single intramuscular injection of betamethasone sodium phosphate associated with betamethasone dipropionate and a PPI (proton pump inhibitor) (rabeprazole $20 \mathrm{mg}$ PO). After 4 weeks of treatment, patients underwent endoscopy and biopsy. We evaluated patients' clinical response as well as the results of endoscopic and histological examinations. Results: After 4 weeks of treatment, all patients (100\%) are reported significant clinical improvement, which was corroborated by the findings on endoscopy and histology. There were no complications or adverse reactions. Conclusions: In this cohort of patients with eosinophilic esophagitis, treatment with a single intramuscular dose of corticosteroids led to complete remission of symptoms and improvement in endoscopic and histological findings.
\end{abstract}

Key words: Treatment of eosinophilic esophagitis, corticotherapy, corticosteroid, eosinophil, Ee.

\section{Introduction}

Ee (Eosinophilic esophagitis) is an inflammatory condition characterized by a dense infiltrate of eosinophils in the esophageal epithelium [1]. The underlying pathophysiology is similar to that of allergic diseases and can progress to a chronic form [2, 3]. The prevalence of Ee has been on the rise and currently affects 43 per 100,000 inhabitants [4]. Ee tends to affect young people between 20 and 40 years old, and is more frequent in men [2, 3, 5]. It is the most common cause of food impaction in young adults [6]. In up to $10 \%$ of cases, there is a family or personal history of allergic disease [7]. Ee has also been shown to be associated with GERD

Corresponding author: Augusto Fey, Ph.D., M.D., Senior Lecturer, research fields: endoscopy and gastroenterology. (gastroesophageal reflux disease) [8], celiac disease [9], and other allergic diseases such as asthma, allergic rhinitis, and atopic dermatitis [10].

The pathogenesis of Ee has not been elucidated, but it has been shown that antigenic stimulation induces the differentiation of eosinophils from precursor cells in the bone marrow [11]. The normal esophageal mucosa is composed of stratified squamous epithelium, which contains lymphocytes, dendritic cells and stem cells, but not eosinophils or other leukocytes. The histological features of Ee are still under debate, with some researchers proposing that the disease is histologically characterized by more than 20 EHPF (eosinophils per high power field) [12], and others suggesting lower cut-offs of $15[13,14]$ or even 5 EHPF [2].

The disease is characterized by a varied spectrum of 
clinical symptoms including dysphagia, food impaction, vomiting, chest pain, nausea, heartburn, epigastric pain, drooling, food intolerance, and swallowing difficulty [15]. More atypical symptoms include cough, sinusitis and pneumonia, and in some situations, symptoms of reflux might be present [16]. As a result, many patients are not correctly diagnosed until many years after their initial presentation [17].

The endoscopic findings of Ee are similar to those of other diseases of the esophagus, but can be normal in $18 \%$ to $24 \%$ of cases [18-20]. The most frequent endoscopic findings are esophageal rings, transverse furrows, longitudinal erosions, swelling, friability, white plaques, stenosis, and polyps, among others [20, 21]. While there is no pathognomonic feature of Ee, there are certain endoscopic findings in a symptomatic patient, which strongly support the diagnosis including transverse rings (48\%), longitudinal furrows (46\%), stenosis (24\%) and esophagus gauge decrease $(12 \%)$ [8]. In order to expedite accurate diagnosis and initiation of management, it is essential that endoscopists are familiar with these characteristic findings [22].

One treatment option for Ee includes drug therapy with corticosteroids, either systemic or topical, which have been shown to induce remission of symptoms as well as histologic improvement [23]. Another therapeutic option is dietary modification [24] which has been shown to lead to clinic and histologic improvement from $75 \%$ to $98 \%$ of patients, as determined by cutaneous and serological tests $[25,26]$. In more advanced cases, a trial of endoscopic esophageal dilation may be considered, but due to the risk of morbidity associated with this procedure, it is restricted to very select cases [27].

In Brazil, the literature on Ee pathology is limited to only a few studies. Therefore, we felt that a more thorough investigation into this disorder is warranted, and focused on inhabitants of South Brazil, as this area is predominantly settled by Europeans descendants who are epidemiologically more prone to
Ee [28].

\section{Objective}

The objective of this study was to report the efficacy of treatment of Ee with a single dose of intramuscular corticosteroid associated with oral PPI.

\section{Materials and Methods}

This was a prospective study of patients who presented with typical symptoms and/or endoscopic findings suggestive of $\mathrm{Ee}$ conducted between September 2011 and September 2013. The study protocol was approved by the Ethics Committee in Research at our institution, and all patients provided written informed consent. All patients with EHPF $\geq$ 15 were included in the study. Patients were excluded if they had EHPF $<15$ or esophageal strictures that required endoscopic dilatation. All patients were treated with a single intramuscular injection of betamethasone sodium phosphate associated with betamethasone dipropionate and an oral PPI (rabeprazole $20 \mathrm{mg}$ once daily). After 4 weeks, patients underwent repeat endoscopy and biopsy to confirm response to treatment. All of the endoscopies and biopsies were performed in the same endoscopic center, by the same endoscopist (the author), and all histological analysis was performed by one pathologist. Patients were followed up for six months.

\section{Results}

We performed 4,251 endoscopies between September 2011 and 2013. Biopsies were performed in 133 patients with clinical or endoscopic features of Ee; of these, we identified 55 patients with EHPF. Of the latter, 21 were excluded because they had stenosis or $<15$ EHPF and the remained were included in the final analysis.

After treatment with a single intramuscular dose of corticosteroid and PPI, all patients (100\%) experienced complete resolution of clinical symptoms and normalization of endoscopic findings, as shown in 
Figs. 1a, 1b, 2a, 2b, 3a, 3b. A complete remission of eosinophilia occurred in 19 patients, whereas the remaining 5 experienced a decrease in EHPF to less than 15 (case 1: 15 to 4; case 2: 20 to 12; case 3: 25 to 8; case 4: 30 to 5 ; case $5: 30$ to 8 ).

During the 6 months of follow up, symptoms recurred in four patients and included food impaction $(\mathrm{n}=2)$ and pain $(\mathrm{n}=2)$. In the two patients presenting

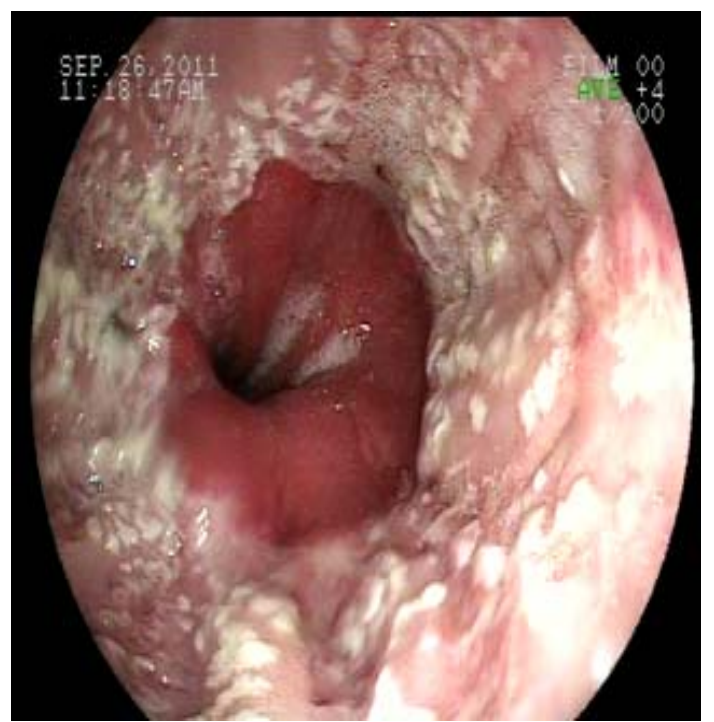

Fig. 1a Ee+moniliasis/ 35 EHPF.

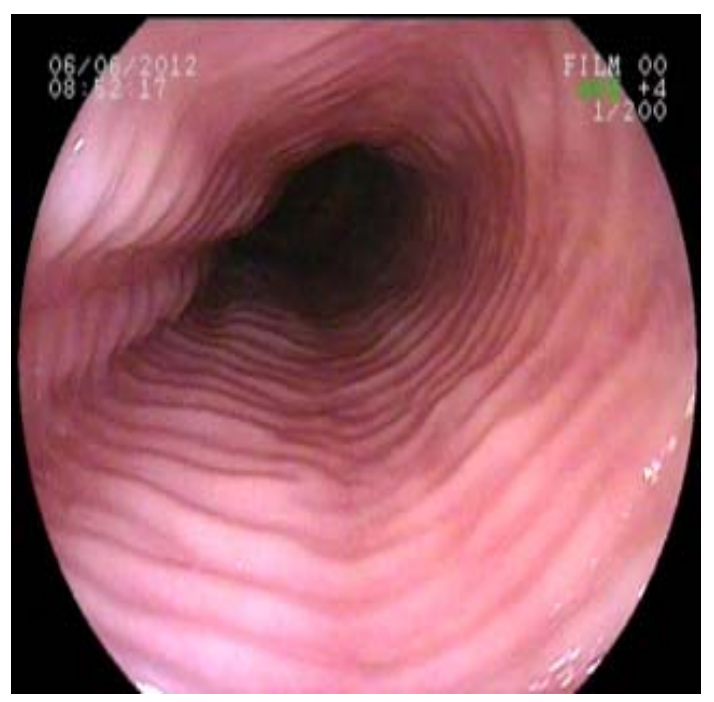

Fig. a Ee/25 EPHF. with food impaction, endoscopic findings were typical of Ee and EHPF was $>15$. The two patients who presented with pain had negative findings on endoscopy and no evidence of eosinophilia.

There were no complications following endoscopy and no adverse effects secondary to treatment.

Endoscopic findings for three patients (before and after treatment) are shown in figures below.

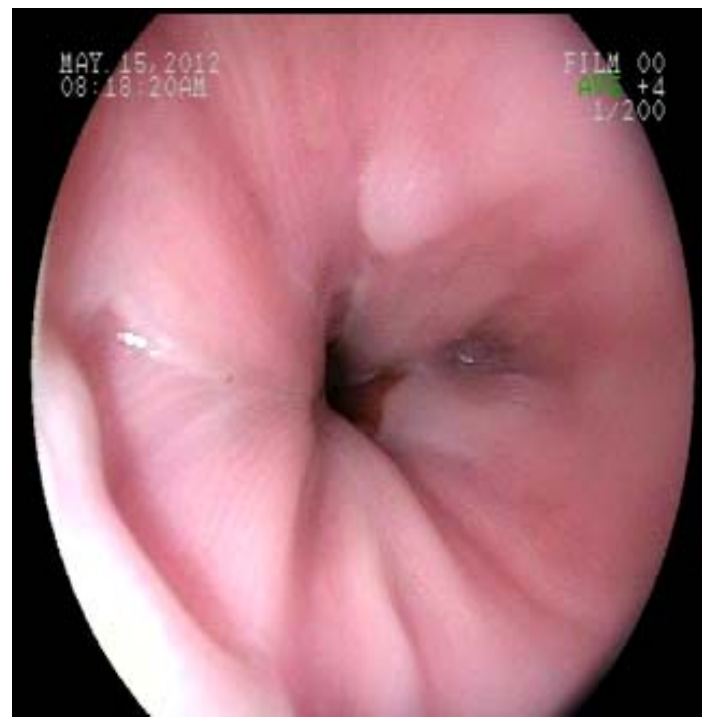

Fig. 1b After treatment/0 EPHF

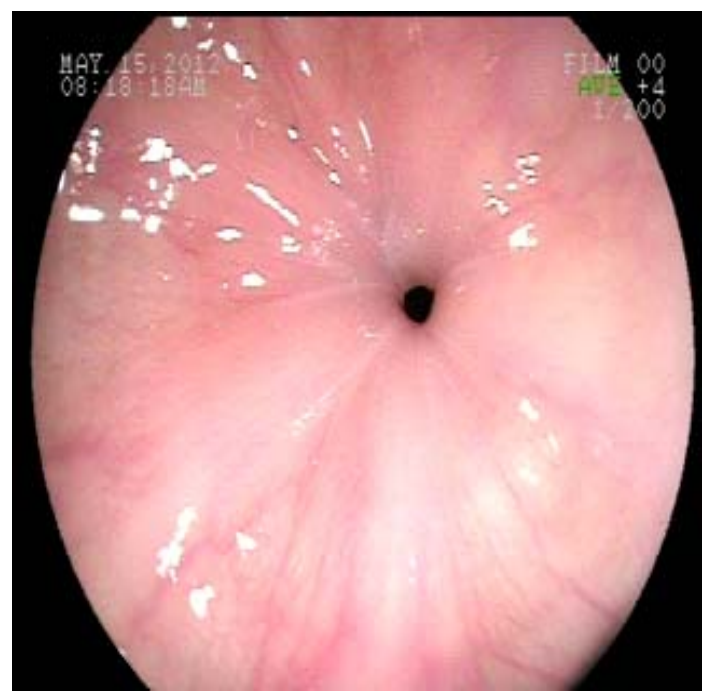

Fig. 2b After treatment/0 EPHF 


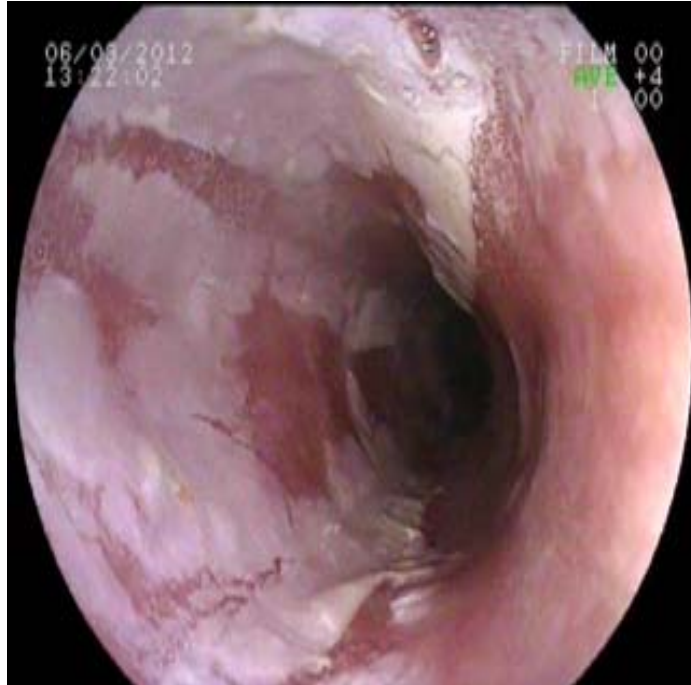

Fig. 3a Ee/30 EHPF.

\section{Discussion}

Eosinophilic esophagitis was first recognized as a distinct clinical entity over twenty years ago. Since its discovery, treatment for this condition has evolved to its current regimen of the " 3 Ds": drugs, diet, and dilation. Only corticosteroids have proven efficient, with most other drugs having only minimal effects. Dietary modification is also important and must be strictly adhered to, which can markedly interfere with patients' quality of life, and in more extreme cases even increase the risk of malnutrition. A greater understanding of the immuno-pathogenesis, natural history, and disease spectrum of Ee will inevitably lead to improved therapeutic outcomes [29].

Recent guidelines from 2007 recommend acid suppression for the treatment of Ee. In addition to PPI-responsive Ee, PPI therapy is also useful for the treatment of Ee secondary to GERD [30]. In Ee, PPI treatment is associated with decreased eosinophil degranulation [31]. These and other studies justify the use of PPIs for the patients in our study.

Previous studies have demonstrated the effectiveness of systemic corticosteroids for the treatment of Ee. In one of the first studies on Ee conducted in 1998, 20 patients with treatment-resistant Ee were treated with $1.5 \mathrm{mg} / \mathrm{kg}$ oral methylprednisolone daily (divided into

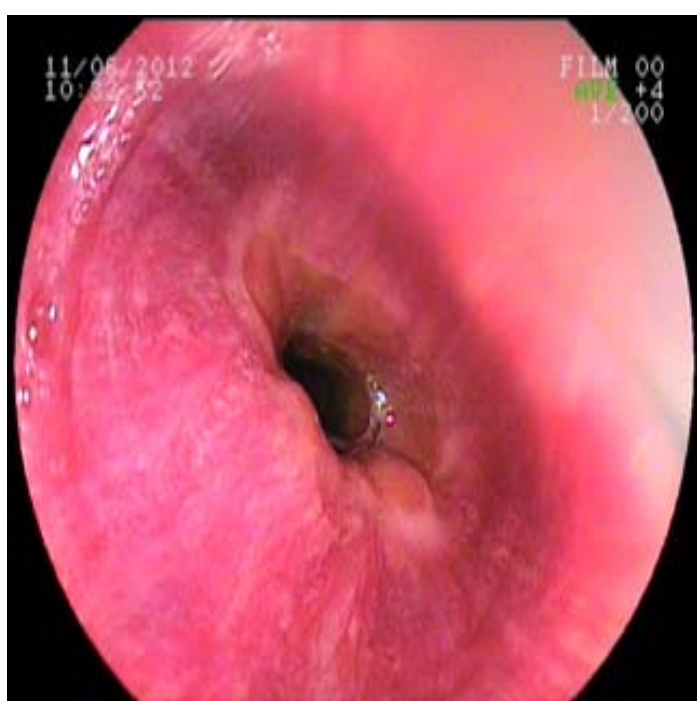

Fig. 3b After treatment/5 EHPF.

twice-daily doses) for 4 weeks. After corticosteroid therapy, all patients with primary Ee showed dramatic clinical and histologic improvement [32]. Another study compared the efficacy of oral prednisone and topical fluticasone in Ee patients, and observed that the prednisone-treated group had a greater degree of histologic improvement [33]. In our case series, treatment with corticosteroids resulted in clinical, endoscopic, and histologic improvement in the absence of side effects. These results suggest that this treatment protocol is a promising alternative to current therapeutic options for Ee.

\section{Conclusions}

In this study, we demonstrated the simplicity, efficacy and safety of Ee treatment with a single intramuscular injection of betamethasone sodium phosphate associated with betamethasone dipropionate. This treatment protocol is superior to alternative therapies based on dietary modification and topical corticosteroids on account of its lower cost, favorable side effect profile, and ability to produce clinical remission that is corroborated by endoscopic and histological findings over a long period of follow up.

\section{Conflict of Interest}

The authors have no conflicts of interest to disclose. 


\section{References}

[1] Potter, J. W., Saeian, K., Staff, D. et al. 2004 "Eosinophilic Esophagitis in Adults: An Emerging Problem with Unique Esophageal Features.” Gastrintest. Endosc. 59: 355-61.

[2] Silva, M. C., Carlos, A. S., Montes, C. G., and Zeitune, J. M. R. 2008. "Esofagite eosinofílica em adultos: (revisão).” RBM Rev. Bras. Med. Set 65 (9): 273-8.

[3] Fey, A., Kotze, L. M., and Serapião, M. 2012. "Eosinophilic Esophagitis: Review.” ACM Arq. Catarin. Med. 41 (2).

[4] Noel, R., Putnam, P. E., and Rothemberg, M. E. 2004. “Eosinophilic Esophagitis.” N. Engl. J. Med. 351: 940-1.

[5] Straumann, A., Spichtin, H. P., Grize, L., Bucher, K. A., Beglinger, C., and Simon, H. U. 2003. "Natural History of Primary Esosinophilic Esophagitis: A Follow up of 30 Adult Patients for up to 11.5 years.” Gastroenterology 125: 1660-9.

[6] Desai, T. K., Stecevic, V., Chang, C.-H., Goldstein, N. S., Badizadegan, K., and Furuta, G. T. 2006. "Association of Eosinophilic Inflamation with Esophageal Food Impaction on Adults.” Gastrintest. Endosc. 61: 785-801

[7] Basavaraju, K. P., and Wong, T. 2008. "Eosinophilic Oesophagitis: A Common Cause of Dysphagia in Adults.” Int. J. Clin. Pract. 62 (7): 1096-107.

[8] Remedios, M., Campbel, C., Jones, D. M., and Kerlin, P. 2006. "Eosinophilic Esophagitis in Adults: Clinical, Endoscopic, Histologic Findings and Response to Treatment with Fluticasone Propionate.” Gastrointest. Endosc. 63: 3-12.

[9] Quaglietta, L., Coccorullo, P., Miele, E., Pascarella, F., Troncone, R., and Straiano, A. 2007. "Eosinophilic Esophagitis and Celíaca Disease: Is There an Association?” Aliment. Pharmacol. Ther. 26: 487-93.

[10] Brown-Whithorn, T. F., and Spergel, J. M. 2010. "The Link between Allergies and Eosinophilic Esophagitis: Implications for Management Strategies.” Expert. Rev. Clin. Immunol. 6: 101-9.

[11] Rothenberg, M. E. 2009. "Biology and Treatment of Eosinophilic Esophagitis.” Gastroenterology 137: 1238-49.

[12] Furuta, G. T., and Straumann, A. 2006. "Review Article: The Pathogenesis and Management of Eosinophilic Oesophagitis.” Aliment. Pharmacol. Ther. 24: 173-82.

[13] Aktins, D., Kramer, R., Capocelli, K., Lovell, M., and Furuta, G. T. 2009. "Eosinophilic Esophagitis: The Newest Esophageal Inflammatory Disease.” Nat Rev Gastroenterol. Hepatol. 6: 267-78.

[14] Lucendo, A. J., Gonzalez-Castillo, S., Guagnozzi, D., Yague-Compadre, J. L., and Arias, A. 2010. "Eosinophilic Esophagitis: Current Aspects of a Recently Recognize Disease.” Gastroenterology Research 3:
52-64.

[15] Fey, A., and Kotze, L. 2014. "Esophageal Eosinophilia: A Prospective Study of Two Years.” American Journal of Gastroenterology 109: S585. New York, NY: Nature Publishing Group.

[16] Katzka, D. A. 2008. "Demographic Data and Symptoms of Eosinophilic Esophagitis in Adults.” Gastrointest Endosc. Clin. N. Am. 18: 25-32.

[17] Lucendo Villarin, A. J. 2009. "Eosinophilic Esophagitis-Clinical Manifestations, Diagnosis and Treatment.” Rev. Esp. Enferm. Dig. 101: 49-54.

[18] Kirsch, R., Bokhary, R., Marcon, M. A., and Cutz, E. 2007. "Activated Mucosal Mast Cells Differentiate Esosinophilic (Allergic) Esophagitis from Gastroesophageal Reflux Disease.” J. Pediatr. Gastroenterol. Nutr. 44: 20-6.

[19] Mackenzie, S. H., Go, M., Chadwick, B., et al. 2009. "Eosinophilic Oesophagitis in Patients Presenting with Dysphagia-A Prospective Analysis.” Aliment. Pharmacol. Ther. 28: 1140-6.

[20] Pacha, S. F., DiBiase, J. K., Kim, H. J., et al. 2007. "Patient Characteristics, Clinical, Endoscopic, and Histologic Findings in Adult Esosinophilic Esophagitis: A Case Series and Systematic Review of a Medical Literature.” Dis. Esophagus. 20 (4): 311-9.

[21] Kotze, L., and Fey, A. 2014. "Endoscopic Classification of Eosinophilic Esophagitis." American Journal of Gastroenterology 109: S563. New York, NY: Nature Publishing Group.

[22] Fox, V. L. 2008. "Eosinophilic Esophagitis: Endoscopic Findings.” Gastrointest. Endosc. Clin. N. Am. 18: 45-57.

[23] Dellon, E. S., Gonsalves, N., Hirano, I., et al. 2013. "CG Clinical Guideline: Evidenced Based Approach to the Diagnosis and Management of Esophageal Eosinophilia and Eosinophilic Esophagitis (EoE)." Am. J. Gastroenterol 108: 679-92.

[24] Wolf, W. A., Jerath, M. R., Sperry, S. L., Shaheen, N. J., and Dellon, E. S. 2014. "Dietary Elimination Therapy is an Effective Option for Adults with Eosinophilic Esophagitis.” Clin. Gastroenterol. Hepatol. 12: 1272-9.

[25] Papadopoulou, A., Koletzko, S., Heuschkel, R., Dias, J. A., Allen, K. J., and Murch, S. H. 2014. "Gastroenterology Committee: Management Guidelines of Eosinophilic Esophagitis in Childhood.” J. Pediatr. Gastroenterol. Nutr. 58: 107-18.

[26] Arias, A., Gonzalez-Cervera, J., Tenias, J. M., and Lucendo, A. J. 2014. "Efficacy of Dietary Interventions for Inducing Histologic Remission in Patients with Eosinophilic Esophagitis: A Systematic Review and Meta-Analysis.” Gastroenterology 146: 1639-48.

[27] Bohm, M. E., and Richter, J. E. 2011. "Review Article: Oesophageal Dilation in Adults with Eosinophilic 


\section{A Novel Therapy of Eosinophilic Esophagitis-Treatment of Eosinophilic Esophagitis Using a Single Dose of Intramuscular Corticosteroid and Proton Pump Inhibitor}

Oesophagitis.” Aliment. Pharmacol. Ther. 33: 748-57.

[28] Chatham, D., Cavender, C. P., and Lieberman, J. A. 2014.

"Racial Disparity in Eosinophilic Esophagitis from a Single, Defined Population.” Ann. Allergy. Asthma. Immunol. 113: 489-91.

[29] Straumann, A. 2014. "Eosinophilic Esophagitis: Emerging Therapies and Future Perspectives." Gastroenterol. Clin. North. Am. 43: 385-94.

[30] Liacouras, C. A., Furuta, G. T., Hirano, I., et al. 2011. "Eosinophilic Esophagitis: Updated Consensus Recommendations for Children and Adults.” J. Allergy. Clin. Immunol. 128: 3-20.

[31] Levine, J., Lu, Y., Carreon, C. K., and Edelman, M. 2015.
"Proton-Pump Inhibitor Treatment in Eosinophilic Esophagitis Is Associated with Decreased Eosinophil Degranulation.” J. Gastrointest. Dig. Syst. 5: 2.

[32] Liacouras, C. A., Wenner, W. J., Brown, K., and Ruchelli, E. 1998. "Primary Eosinophilic Esophagitis in Children: Successful Treatment with Oral Corticosteroids." $J$. Pediatr. Gastroenterol. Nutr. 26 (4): 380-5.

[33] Schaefer, E. T., Fitzgerald, J. F., Molleston, J. P., Croffie, J. M., Pfefferkorn, M. D., Corkins, M. R., and Gupta, S. K. 2008. "Comparison of Oral Prednisone and Topical Fluticasone in the Treatment of Eosinophilic Esophagitis: A Randomized Trial in Children.” Clin Gastroenterol Hepatol 6: 165-73. 